\title{
Accurate Analysis of Lithium Isotopic Ratios in Geological Samples with High Precision
}

\author{
JIE LIN, YONGSHENG LIU
}

State Key Laboratory of Geological Processes and Mineral Resources, School of Earth Sciences, China University of Geosciences (Wuhan)

Lithium, an emerging tracer tool, has gained more and more researchers' attention. There are two aspects in getting $\mathrm{Li}$ isotopic ratios: bulk analysis and in situ micro-analysis. We have built the method about accurate measurements of Li isotopic ratios by SN-MCICP-MS and microanalysis of $\mathrm{Li}$ isotopic ratios by LAMC-ICP-MS.

1. Accurate determination of $\mathrm{Li}$ isotopic ratios by SN-MC-ICP-MS with low-blank, low-memory

For the determination of $\mathrm{Li}$ isotopic ratios by $\mathrm{MC}$ ICP-MS, the accuracy of Li isotopic ratios is generally limited by the high Li instrumental blank and serious memory effect. In order to solve the problem, we found that Li blank can be magically reduced by a factor of 15 - 70 by the addition of a $5 \% \mathrm{NaCl}$ rinse step. With the elimination of Li instrumental blank and memory effect, there is not a large deviation even though the $\mathrm{Li}$ concentration and $\mathrm{HNO}_{3}$ concentration of sample and standard are not strictly matched. Based on this conclusion, a non-strict matrix-matched method is built to analyze $\mathrm{Li}$ isotopic ratios.

2. Accurate measurement of $\mathrm{Li}$ isotopic ratios by LA-MC-ICP-MS with non-matrix-matched calibration method

After investigating the distribution of $\mathrm{Li}$ ions in plasma, the ${ }^{7} \mathrm{Li} /{ }^{6} \mathrm{Li}$ ratio stability can be improved from 4- to 13 -fold by "sacrificing" $5 \%$ of signal intensity when shallower sampling depth or higher sample gas flow rate are applied. In the analysis of $\mathrm{Li}$ isotopic ratios, the intensity mismatch effect can be reduced when ${ }^{7} \mathrm{Li}$ intensity and signal/background ratio were higher than $0.2 \mathrm{~V}$ and 214 , respectively. With the water addition before and after the ablation cell, the $\mathrm{Li}$ isotopes of tourmalines can be non-matrix-matched calibrated by ns- and fs-LA-MC-ICP-MS, respectively. 